\title{
Soil humic acids may favour the persistence of hexavalent chromium in soil
}

\author{
Liviana Leita $^{\mathrm{a}, *}$, Alja Margon ${ }^{\mathrm{a}}$, Arnold Pastrello ${ }^{\mathrm{a}}$, Iztok Arčon ${ }^{\mathrm{b}, \mathrm{c}}$, Marco Contin ${ }^{\mathrm{d}}$, Davide Mosetti ${ }^{\mathrm{a}}$ \\ a A.R.C. Agricultural Research Council-Research Group on Soil-Plant Systems, Via Trieste 23, 34170 Gorizia, Italy \\ ${ }^{\mathrm{b}}$ University of Nova Gorica, Vipavska 13, SI-5000 Nova Gorica, Slovenia \\ ' Jožef Stefan Institute, Jamova 39, SI-1000 Ljubljana, Slovenia \\ ${ }^{\mathrm{d}}$ Dipartimento di Scienze Agrarie e Ambientali, University of Udine, Via delle Scienze 208, 33100 Udine, Italy \\ Humic acids (HAs) did not induce reduction of $\mathrm{Cr}(\mathrm{VI})$ to its trivalent chemical form, as the interaction between $\mathrm{Cr}(\mathrm{VI})$ and $\mathrm{HAs}$ rather led to the \\ formation of $\mathrm{Cr}(\mathrm{VI})-\mathrm{HAs}$ micelles via supramolecular chemical processes.
}

\section{A R T I C L E I N F O}

\section{Article history:}

Received 4 March 2008

Received in revised form

20 January 2009

Accepted 22 January 2009

\section{Keywords:}

Chromium

Humic acids

UV-Vis spectroscopy

Differential pulse voltammetry

X-ray absorption spectroscopy

\begin{abstract}
A B S T R A C T
The interaction between hexavalent chromium $\mathrm{Cr}(\mathrm{VI})$, as $\mathrm{K}_{2} \mathrm{CrO}_{4}$, and standard humic acids (HAs) in bulk solution was studied using three complementary analytical methods: UV-Visible spectroscopy, X-ray absorption spectroscopy and differential pulse stripping voltammetry. The observed UV-Vis and X-ray absorption spectra showed that, under our experimental conditions, HAs did not induce reduction of $\mathrm{Cr}(\mathrm{VI})$ to its trivalent chemical form. The interaction between $\mathrm{Cr}(\mathrm{VI})$ and $\mathrm{HAs}$ has rather led to the formation of $\mathrm{Cr}(\mathrm{VI})-\mathrm{HAs}$ micelles via supramolecular chemical processes. The reported results could contribute towards explaining the relative persistence of ecotoxic hexavalent chromium in soils.
\end{abstract}

(c) 2009 Elsevier Ltd. All rights reserved.

\section{Introduction}

Chromium exists in oxidation states ranging from 0 to +6 , with the +3 and +6 states prevailing in soil and groundwater ecosystems. The presence and fate of chromium in these systems is of concern mainly due to the high toxicity and carcinogenicity of the hexavalent form towards web-biota.

Trivalent chromium $\mathrm{Cr}(\mathrm{III})$ is undoubtedly the most thermodynamically stable form of chromium in soil, as it readily precipitates as chromium hydroxide $\left(\mathrm{Cr}(\mathrm{OH})_{3}\right)$ and iron-chromium hydroxide $\left((\mathrm{Fe}, \mathrm{Cr})(\mathrm{OH})_{3}\right)$ or becomes immobilised after sorption (e.g. adsorption and surface precipitation) onto soil colloids, a mechanism strongly related to their peculiarities, such as the clay-oxideshydroxides quality and content, inorganic carbon, cation exchange capacity and pH conditions (Covelo et al., 2007; Flogeac et al., 2007; James and Bartlett, 1983; Palmer and Puls, 1994; Stewart et al., 2003).

Even though naturally elevated levels of hexavalent chromium $\mathrm{Cr}(\mathrm{VI})$ have been found in the soils and groundwater of Paradise Valley, Arizona (Robertson, 1975) and in minerals of a desert area in Chile (Ericksen, 1983), distressing amounts of $\operatorname{Cr}(\mathrm{VI})$ in soil are

\footnotetext{
* Corresponding author. Tel.: +39 0481 522041; fax: +39 0481520208.

E-mail address: liviana.leita@entecra.it (L. Leita).
}

largely restricted to sites contaminated by anthropogenic activities and mainly due to poor storage and improper disposal practices at industrial facilities, together with the use of several wood preservatives and pigments.

After entering the soil, $\mathrm{Cr}(\mathrm{VI})$ remains thermodynamically metastable in the pore solution and is generally much more mobile in soil than $\mathrm{Cr}(\mathrm{III})$, since $\mathrm{Cr}(\mathrm{VI})$ oxyanions (chromate $\mathrm{CrO}_{4}^{2-}$, bichromate $\mathrm{HCrO}^{4-}$, and dichromate $\mathrm{Cr}_{2} \mathrm{O}_{7}^{2-}$ ) are not sorbed onto soil colloids under alkaline to sub-neutral conditions. On the other hand, transport and reduction of $\mathrm{Cr}(\mathrm{VI})$ in soil ultimately reflects the interdependent influences of chemical, physical and microbial processes in the contaminated soil. More than three decades ago Bartlett and Kimble (1976) and recently also several other scientists (Banks et al., 2006; Jardine et al., 1999), recognised that $\mathrm{Cr}(\mathrm{VI})$ can be rapidly reduced to $\mathrm{Cr}(\mathrm{III})$ by soil organic matter. In fact, $\mathrm{Cr}(\mathrm{VI})$, being a strong oxidant, can be readily reduced to $\mathrm{Cr}(\mathrm{III})$ in the presence of various electron donors (Nakayasu et al., 1999; Palmer and Wittbrodt, 1991). However, even when dealing with propitious soil composition (i.e. electron donor chemical domains, competing ions and soil texture) and favourable physical conditions, $\mathrm{Cr}(\mathrm{VI})$ may persist, especially in organic soils, for prolonged periods of time, even years (Palmer and Wittbrodt, 1991).

Humic acids (HAs) are natural carbon-rich biopolymers ubiquitous in terrestrial and aquatic environments, whose multiple properties seem to be purpose-built for many life-sustaining 
functions, from agriculture to industry, environment and biomedicine (Peña-Méndez et al., 2005). Even though HAs are still a subject of a long-standing research and great efforts are being made to elucidate their defined structure, present knowledge indicates that their basic binding block is in fact a hydrophobic framework of aromatic rings with linked alcohol, amide, amine, carboxylic, carbonyl, phenolic, hydroxyl and quinone functional groups, all interlinked by flexible carbon chains. Due to this polyfunctionality, HAs represent a strongly $\mathrm{pH}$-dependent reservoir of electron donors/acceptors, which could hypothetically contribute to reduction of several inorganic and organic contaminants. In fact, one of the most significant properties of HAs or/and HA-like substances is their ability to interact with xenobiotics to form complexes of different solubility and chemical and biochemical stability. HAs can therefore affect the uptake, bioavailability, transport, fixation and toxicity of xenobiotics in the environment (Borges et al., 2005; Campitelli et al., 2006; Lubal et al, 1998).

This paper focuses on the elucidation of interactions of $\mathrm{Cr}(\mathrm{VI})$ with standard HAs under sub-neutral conditions using three complementary analytical methods: UV-Visible (UV-Vis) spectroscopy, X-ray absorption spectroscopy (EXAFS-Extended X-ray Absorption Fine Structure, and XANES-X-ray Absorption Near Edge Structure) and Differential Pulse Stripping (DPS) voltammetry.

\section{Materials and methods}

\subsection{Humic acids (HAs) and chromate working solutions}

A reference humic acids sample (1S103H) provided by the International Humic Substances Society (IHSS) collection was used. Humic acids (HAs) were extracted from air-dried Pahokee peat and purified and lyophilised according to IHSS protocols (www.ihss.gatech.edu). The HAs' lyophilised powder was solubilised in $0.5 \mathrm{M} \mathrm{NaOH}$ $(1: 10 \mathrm{w} / \mathrm{v})$, adjusted to $\mathrm{pH} 6.5$ with acetate buffer, and analysed for organic carbon content by the Walkley-Black procedure. The HAs solution was then diluted to obtain the working solution containing $300 \mu \mathrm{g}$ of organic carbon $\mathrm{ml}^{-1}$.

Ten $\mathrm{ml}^{-1}$ of a $10 \mu \mathrm{M} \mathrm{K} \mathrm{KrO}_{4}$ working solution was prepared by diluting the potassium chromate standard as primary standard by ICP-OE Spectrometry. The $\mathrm{pH}$ of the working solution was adjusted to 6.5 with $0.5 \mathrm{M} \mathrm{KOH}$.

The concentrations of $\mathrm{HAs}$ (as organic carbon) and $\mathrm{K}_{2} \mathrm{CrO}_{4}$ used during the study were chosen accordingly to actual environmental conditions found in soils contaminated with hexavalent chromium.

All used chemicals were of analytical-reagent grade quality.

The experiments were performed using an excess of HAs over $\mathrm{Cr}(\mathrm{VI})$, according to Wittbrodt and Palmer (1996).

\subsection{UV-Vis spectrophotometric titration}

The spectra of $10 \mu \mathrm{M} \mathrm{K} \mathrm{CrO}_{4}$ at $\mathrm{pH} 6.5$ without and with added increasing concentrations of HAs were recorded in the region between 200 and $600 \mathrm{~nm}$, where the main chromate absorption bands occur (Uyguner and Bekbolet, 2004). Aliquots $(50 \mu \mathrm{l})$ of the HAs stock solution, corresponding to $15 \mu \mathrm{g}$ of organic carbon, were added stepwise to the chromate solution and measurements were performed after $30 \mathrm{~min}$.

Due to the very slow kinetics of complexation equilibria between $\mathrm{Cr}(\mathrm{III})$ and humate ligands (Fukushima et al., 1997), we carried out experiments up to 2 weeks after addition of HAs to $\mathrm{Cr}(\mathrm{VI})$ solutions. However, under our experimental conditions, the reaction appeared to be complete after $20 \mathrm{~min}$, as the $\lambda \max _{\mathrm{Abs}}$ peak of chromate progressively decreased within $20 \mathrm{~min}$ after HAs addition, but remained stable for 2 weeks thereafter.

UV-Vis spectra were recorded at room temperature on a Varian Cary 1E UV-Vis spectrophotometer in 1-cm quartz sample cells. Distilled water or solutions containing HAs aliquots were used as blanks.

\subsection{X-ray absorption spectroscopy}

$\mathrm{X}$-ray absorption spectra in the energy region of the $\mathrm{Cr}$ K-edge were measured in transmission detection mode at E4 beamline of the HASYLAB synchrotron facility at DESY in Hamburg. The station provided a focused beam from an Au-coated torroidal mirror, with a focal spot of about $5 \mathrm{~mm} \times 1 \mathrm{~mm}$ on the sample. A Si(111) double crystal monochromator was used with about $1 \mathrm{eV}$ resolution at the $\mathrm{Cr}$ K-edge $(5989 \mathrm{eV})$. Harmonics were effectively eliminated by a plane Au-coated mirror, and by a slight detuning of the second monochromator crystal, keeping the intensity at $60 \%$ of the rocking curve with the beam stabilisation feedback control. The intensity of the incident and transmitted X-ray beams were measured by three consecutive ionisation chambers; the first was filled with 900 mbar of $\mathrm{N}_{2}$, while the second and third were filled with $\mathrm{Ar}$ at respective pressures of 240 mbar and 430 mbar. The samples were mounted between the first and second ionisation cell. The exact energy calibration was established with simultaneous absorption measurements on metallic $\mathrm{Cr}$ inserted between the second and third ionisation cell. The absorption spectra were collected within the $-250 \mathrm{eV}-1000 \mathrm{eV}$ interval of the $\mathrm{Cr}$ K-edge. In the XANES region equidistant energy steps of $0.3 \mathrm{eV}$ were used, while for the EXAFS region equidistant $k$-steps $\left(\Delta k \approx 0.03 \AA^{-1}\right)$ were adopted with an integration time of $2 \mathrm{~s} / \mathrm{step}$. Two experimental runs were superimposed to improve the signal-to-noise ratio and check reproducibility of measured spectra.

A $50 \mu \mathrm{M} \mathrm{K}_{2} \mathrm{CrO}_{4}$ solution at $\mathrm{pH} 6.5$ with or without HAs was inserted in a variablelength liquid absorption cell with $0.3 \mathrm{~mm}$ thick lucite windows. The optimal total absorption thickness $(\mu \mathrm{d})$ of about 2 was found with a $0.6 \mathrm{~mm}$ thick sample layer in the cell. The obtained $\mathrm{Cr}$ K-edge jump was 0.8 . For comparison, the absorption spectra of the reference $\mathrm{Cr}$ samples with known atomic structure and $\mathrm{Cr}$ valence state $\left(\mathrm{Cr}_{2} \mathrm{O}_{3}\right.$, $\mathrm{Ca}_{10} \mathrm{Cr}_{6} \mathrm{O}_{25}$ and $\mathrm{CaCrO}_{4}$ ) were measured. For each reference sample micronised powder was homogeneously mixed with micronised BN powder and pressed in pellets with the total absorption thickness of about 1.5 above the $\mathrm{Cr}$ K-edge.

The quantitative analysis of $\mathrm{Cr}$ K-edge XANES and EXAFS spectra was performed with the IFEFFIT program packages ATHENA and ARTEMIS (Ravel and Newville, 2005) using the FEFF6 code (Rehr et al., 1992) in which the photoelectron scattering paths were calculated $a b$ initio from a presumed distribution of neighbour atoms.

\subsection{Electrochemical analysis: Amperometric titration}

Electrochemical analyses, as differential pulse stripping (DPS) voltammetry, were performed in concomitance with spectrophotometric ones.

Since it is well known that HAs' polyelectrolytic nature causes severe interferences in nearly all methods for the determination of chromium species in solution, evaluation of possible interferences at the electrodic surfaces was one of the main aspects to be considered (Korolczuk and Grabarczyk, 2002; Leita et al., 2001, 2003). Moreover, since HAs are also known to contain quinoid moieties, a series of DPS measurements were performed in the absence and in the presence of HAs in $1 \mathrm{mM}$ quinone solution to verify the occurrence of any possible electronic passivation due to adsorption HAs at the surface of the working electrode. The obtained results showed that, under our experimental conditions, no interferences at the working electrode occurred. The electroactive solution at $\mathrm{pH} 6.5$ was composed by mixing $10 \mu \mathrm{M} \mathrm{K}_{2} \mathrm{CrO}_{4}$ and $100 \mu \mathrm{M} \mathrm{KNO}_{3}$ as the supporting electrolyte. Aliquots of HAs were stepwise added to the chromium solution. The samples were bubbled with $\mathrm{N}_{2}$ for $10 \mathrm{~min}$ in order to remove $\mathrm{O}_{2}$, and left to equilibrate for $30 \mathrm{~min}$ before recording. Experimental conditions were as follows: $-1.7 \mathrm{~V}$ deposition potential, $60 \mathrm{~s}$ deposition time, $30 \mathrm{~s}$ equilibration time, $-1.7 \mathrm{~V}$ initial potential, $-0.8 \mathrm{~V}$ final potential, $13.3 \mathrm{mV} / \mathrm{s}$ scan rate, $4 \mathrm{mV}$ scan increment, medium drop size, $50 \mathrm{mV}$ pulse height (Korolczuk and Grabarczyk, 2002).

The used polarographic analyser was an EG\&G Research 384B model, connected to a 303A EG\&G polarographic cell with a three-electrode system (HMDE working electrode with a Pt wire as counter electrode and a $\mathrm{Ag} / \mathrm{AgCl}$, sat. $\mathrm{KCl}$ as the reference electrode).

\section{Results and discussion}

\subsection{UV-Vis spectrophotometric titration}

The UV-Vis spectra of chromate revealed two intense absorption bands at $\lambda \max _{\mathrm{Abs}} 277$ and $\lambda \max _{\mathrm{Abs}} 351 \mathrm{~nm}$, respectively (Fig. 1). In accordance with the results of detailed studies by Takehira et al.(2004)

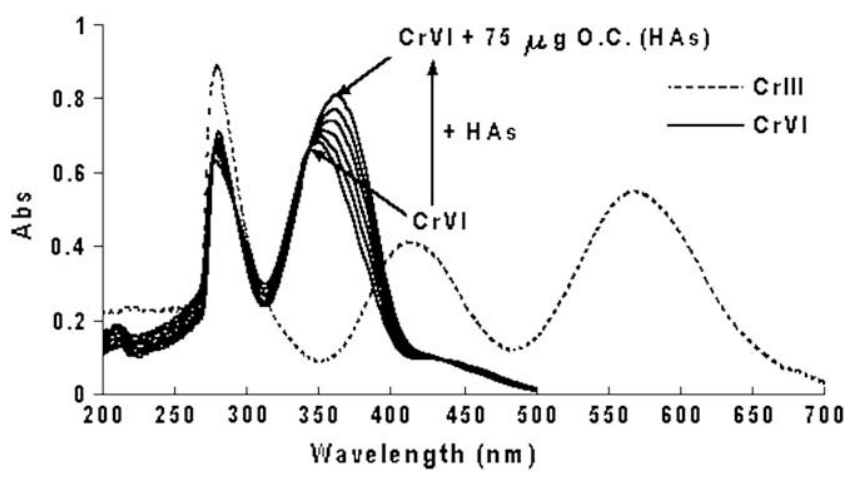

Fig. 1. UV-Vis curves of spectrophotometric titration of $10 \mu \mathrm{M} \mathrm{K}{ }_{2} \mathrm{CrO}_{4}$ before and after addition of HAs. The dashed line represents the spectra of trivalent chromium. 
and Bensalem et al. (1997), these bands were assigned to $\mathrm{O}-\mathrm{Cr}(\mathrm{VI})$ electronic charge transfer of chromate species in a tetrahedral conformational structure.

Stepwise addition of HAs to the chromate solution caused a progressive increase of both absorption peaks with a concomitant shift towards higher wavelength values (up to $4 \mathrm{~nm}$ and $13 \mathrm{~nm}$, respectively). After addition of $75 \mu \mathrm{g}$ of organic carbon, spectra profiles did not change any more, even after adding subsequential aliquots of HAs. These analytical responses indicated that, under our experimental conditions, HAs promoted the probability of intramolecular $\mathrm{O}-\mathrm{Cr}(\mathrm{VI})$ electronic charge transfer together with an energetic benefit, without inducing reduction of $\mathrm{Cr}(\mathrm{VI})$ to $\mathrm{Cr}(\mathrm{III})$. As comparatively shown in Fig. 1, we did not observe any absorption bands at 425 and $583 \mathrm{~nm}$ assigned to the typical octahedral $\mathrm{Cr}$ (III) structure (Takehira et al., 2004). The reduction of $\mathrm{Cr}(\mathrm{VI})$ is strongly $\mathrm{pH}$-dependent. In their work on reduction of $\mathrm{Cr}(\mathrm{VI})$ by soil humic acids, Wittbrodt and Palmer (1996) reported that, under their experimental conditions, reduction of $\mathrm{Cr}(\mathrm{VI})$ occurred at all values of $\mathrm{pH}$ in the range of 2-7. We verified daily by spectrophotometric scan the reduction rate of hexavalent chromium in batch experiments throughout 2 weeks. We found that only neglectable reduction of hexavalent chromium to the trivalent form occurred within $20 \mathrm{~min}$ after the first addition of HAs. In addition, the neglectable reduction rate of hexavalent chromium has also been confirmed on the basis of the thermodynamic approach reported by Wittbrodt and Palmer (1996), where the reduction of hexavalent chromium was observed, but neglectable in the $\mathrm{pH}$ range from 5 to 7.

However, according to Safavi and Abdollahi (2001) and Berlett et al. (2000), $\lambda \max _{\mathrm{Abs}}$ shifts recorded together with the three isosbestic points at $285 \mathrm{~nm}, 350 \mathrm{~nm}$ and $405 \mathrm{~nm}$ indicated quantitative conversion of free $\mathrm{Cr}(\mathrm{VI})$ to the $\mathrm{Cr}(\mathrm{VI})-\mathrm{HAs}$ product.

\subsection{X-ray absorption spectroscopy (XANES, EXAFS)}

Actually, interaction between humic acids containing predominantly negatively charged functional groups with anionic chromate chemical species would not be expected.

X-ray absorption spectroscopy was used to improve the knowledge of the $\mathrm{O}-\mathrm{Cr}(\mathrm{VI})$ charge transfer and eventual structural distortion of tetrahedral chromates as consequence of interaction

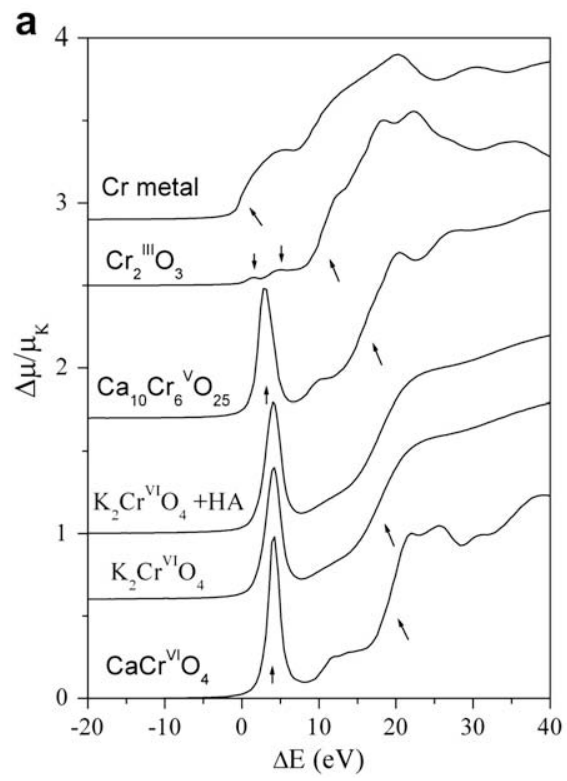

with HAs. Normalised $\mathrm{Cr}$ K-edge XANES spectra of the two $\mathrm{Cr}$ samples and reference compounds with known chromium coordination and oxidation states are shown in Fig. 2a and b. The shape of the K-edge and the pre-edge resonances are characteristic for the local symmetry of the investigated atom and can be used as fingerprints in identification of its local structure (Arčon et al., 1998; Bianconi et al., 1991; Lytle et al., 1988; Pantelouris et al., 2004; Wong et al., 1984). Tetrahedrally coordinated $\mathrm{Cr}(\mathrm{VI})$ cations with $3 \mathrm{~d}^{0}$ ground state electronic configuration in $\mathrm{CaCrO}_{4}, \mathrm{Ca}_{10} \mathrm{Cr}_{6} \mathrm{O}_{25}$ and in $\mathrm{CrO}_{4}^{2-}$ cluster in aqueous solution exhibit a characteristic isolated pre-edge peak, which can be assigned to the electron transition from $\mathrm{Cr}$ 1s core level to the lowest unoccupied tetrahedral molecular orbital 7t $\mathrm{t}_{2}$ (Arčon et al., 1998; Bianconi et al., 1991). On the other hand, octahedrally coordinated $\mathrm{Cr}(\mathrm{III})$ cations in $\mathrm{Cr}_{2} \mathrm{O}_{3}$ that possess an inversion centre, exhibit a different edge shape with two weak resonances in the pre-edge region assigned to transitions of $1 \mathrm{~s}$ electron into unoccupied $t_{2 g}$ and $e_{g}$ bands with octahedral symmetry (Pantelouris et al., 2004). In addition, the valence state of $\mathrm{Cr}$ cations can be deduced from the energy shift of the absorption edge or from the pre-edge absorption features (Arčon et al., 1998; Pantelouris et al., 2004).

From the spectra of the $\mathrm{Cr}_{2} \mathrm{O}_{3}, \mathrm{Ca}_{10} \mathrm{Cr}_{6} \mathrm{O}_{25}$ and $\mathrm{CaCrO}_{4}$ reference samples which display III, $\mathrm{V}$ and $\mathrm{VI}$ chromium oxidation states respectively, we found $\mathrm{Cr}$ K-edge shifts of about $3 \mathrm{eV}$ per valence state, while the shift of the tetrahedral pre-edge resonance (in $\mathrm{Ca}_{10} \mathrm{Cr}_{6} \mathrm{O}_{25}$ and $\mathrm{CaCrO}_{4}$ ) was $1.2 \mathrm{eV}$ per valence state, in agreement with previous observations (Arčon et al., 1998; Wong et al., 1984). The XANES spectra of $\mathrm{CrO}_{4}^{2-}$ with added HAs exhibited identical $\mathrm{Cr}$ K-edge profiles as that of $\mathrm{CrO}_{4}^{2-}$ without HAs. The characteristic pre-edge resonance clearly indicates that $\mathrm{Cr}$ in solution remained tetrahedrally coordinated (Fig. 2a). From the energy position of the pre-edge resonance and the $\mathrm{Cr}$ K-edge we could deduce that the valence state of chromium in the samples is $\mathrm{Cr}(\mathrm{VI})$. Even after detailed inspection we did not find any significant difference between the spectra of $\mathrm{CrO}_{4}^{2-}$ with and without HAs, which clearly demonstrated that local symmetry and valence state of hexavalent $\mathrm{Cr}$ in the aqueous solution did not change due to interaction of $\mathrm{CrO}_{4}^{2-}$ with $\mathrm{HAs}$ and that its valence state remained VI.

In order to verify whether the interaction between HAs and $\mathrm{CrO}_{4}^{2-}$ would have involved structural modifications, we measured

b

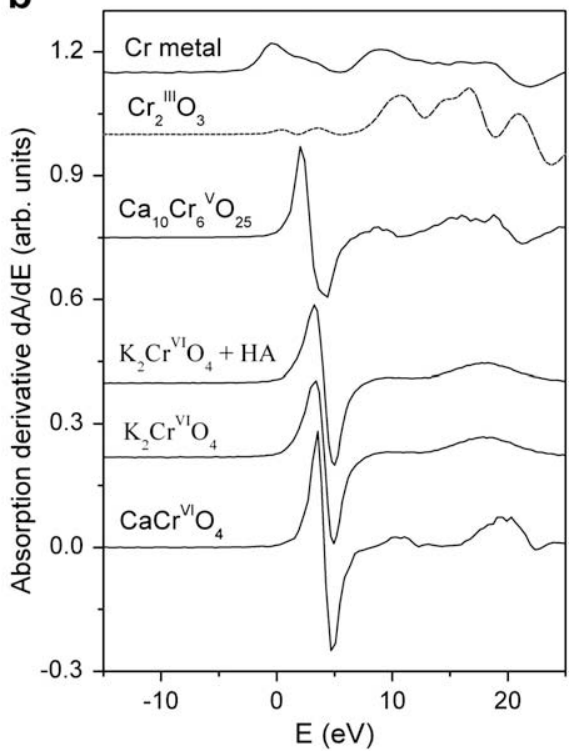

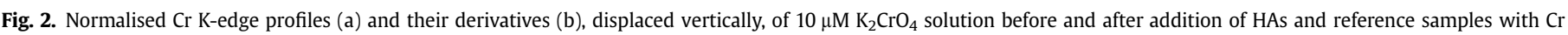
valence state III, V and VI. The energy scale is relative to the $\mathrm{Cr}$ K-edge in metal $(5989.0 \mathrm{eV})$. Arrows denote the positions of the absorption edge and pre-edge resonances. 
Cr K-edge EXAFS spectra, which provides information on the local structure around $\mathrm{Cr}$ atoms in the samples. The comparison of the measured EXAFS spectra of $0.20 \mathrm{mM} \mathrm{K}_{2} \mathrm{CrO}_{4}$ solution before and after addition of HAs showed no structural changes in the local $\mathrm{Cr}$ neighbourhood: both spectra were identical within the noise level. Fourier transform of EXAFS spectra exhibited a single peak that originates from scattering of the photoelectron on the first coordination shell of $\mathrm{Cr}$ neighbour atoms (Fig. 3).

As expected, no significant signal caused by photoelectron scattering from atoms in the second (hydration) coordination sphere was found since the EXAFS signal from such a disordered coordination shell smears out. No additional signal was found in the second $\mathrm{Cr}$ coordination sphere when HAs were present in aqueous solution. It should be noted, however, that this result did not exclude the presence of $\mathrm{HA}$ molecules in close proximity to the $\mathrm{CrO}_{4}^{2-}$ compound, since an eventual weak coordinative bond between $\mathrm{CrO}_{4}^{2-}$ and $\mathrm{HAs}$ molecules would not give a detectable EXAFS signal.

To obtain the structural parameters of the local $\mathrm{Cr}$ neighbourhood we constructed an EXAFS model that included all single scattering paths within a tetrahedral $\mathrm{CrO}_{4}^{2-}$ cluster. We introduced four variable parameters in the model: the shell coordination number $(N)$, the distance $(R)$, the Debye-Waller factors $\left(\sigma^{2}\right)$ of $\mathrm{Cr}-\mathrm{O}$ neighbours and the shift of energy origin $\Delta E_{0}$. The amplitudereduction factor $\left(S_{0}^{2}=0.85\right)$, determined on the spectrum of $\mathrm{Cr}_{2} \mathrm{O}_{3}$ reference compound, was fixed during the fit. A very good agreement between the model and the experimental spectrum was found in the $k$ range of $3-12 \AA^{-1}$, and the $R$ range from $1.3 \AA$ to $2.3 \AA$. A complete list of best-fit parameters is given in Table 1 .

The structural parameters of the $\mathrm{CrO}_{4}^{2-}$ complex in aqueous solution before and after the addition of HAs were unchanged, and agree with previously reported values for the complex in water (Bianconi et al., 1991). Note that the $\mathrm{Cr}(\mathrm{VI})-\mathrm{O}$ bond distance of $1.61 \AA$ in the $\mathrm{Cr}(\mathrm{VI}) \mathrm{O}_{4}$ complex is much shorter than that in a typical $\mathrm{Cr}(\mathrm{III})-\mathrm{O}$ bond, as for example in $\mathrm{Cr}_{2} \mathrm{O}_{3}$, where $\mathrm{Cr}(\mathrm{III})$ is octahedrally coordinated to six oxygen atoms, of which four are located at the distance of $1.95 \AA$ and two at $2.00 \AA$.

The $\mathrm{Cr}$ K-edge EXAFS results therefore clearly showed that interaction with HAs had not induced any structural modifications of the $\mathrm{CrO}_{4}^{2-}$ complex.

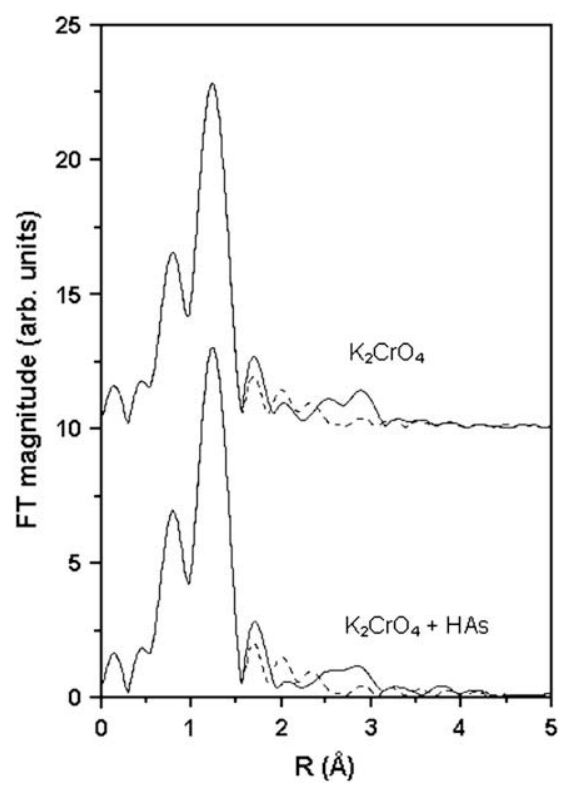

Fig. 3. Fourier transform of $k^{3}$-weighted $\mathrm{Cr}$ EXAFS spectra calculated in the $k$ range of 4-14 $\AA^{-1}$. Experiment: solid line; EXAFS model: dashed line.
Table 1

Quantitative results of $\mathrm{Cr}$ K-edge EXAFS analysis, showing the composition of the nearest coordination shells around $\mathrm{Cr}$ atoms in $\mathrm{CrO}_{4}^{2-}$ complex in aqueous solution with and without HAs.

\begin{tabular}{lllll}
\hline Substance neighbours & $N$ & $R(\AA)$ & $\sigma^{2}\left(\AA^{2}\right)$ & $R$-factor \\
\hline Without HAs & $4.2 \pm 0.3$ & $1.61 \pm 0.01$ & $0.005 \pm 0.001$ & 0.0079 \\
With HAs & $4.2 \pm 0.3$ & $1.61 \pm 0.01$ & $0.005 \pm 0.001$ & 0.0094 \\
\hline
\end{tabular}

The best-fit values were in both cases obtained with the $\Delta E_{\mathrm{o}}$ shift $(3.6 \pm 0.5 \mathrm{eV})$.

\subsection{Electrochemical analysis: Amperometric titration}

Electrochemical methods such as polarography and voltammetry are widely used for trace element analyses in aquatic systems, due to their high sensitivity and reliability. However, even though the specific potentialities of voltammetric techniques for the characterisation of all kinds of chemical complexation reaction have been recognised for a long time, the application of voltammetry in natural polyelectrolyte systems is quite unusual. In this work, the interaction between $\mathrm{Cr}(\mathrm{VI})$ and HAs was investigated by DPS voltammetry, carried out in concomitance with UV-Vis measurements. The $I / V$ curves from amperometric titration showed a very definite $\mathrm{Cr}(\mathrm{VI})$ peak current $\left(I_{\mathrm{p}}\right)$ at $-1.292 \mathrm{~V}$ (Fig. 4$)$, which decreased together with an appreciable shift $(\Delta E 70 \mathrm{mV})$ towards more negative potential values after the first addition of HAs. Stepwise additions of HAs caused a progressive $I_{\mathrm{p}}$ depression without further shifts towards more negative potential values. Similarly to results obtained during the UV-Vis investigation, the sigmoidal shape of the $I / V$ wave got depleted when a $6.5: 1 \mu \mathrm{g}$ organic carbon $/ \mu \mathrm{g} \mathrm{Cr}(\mathrm{VI})$ ratio was reached. The recorded chemical shift cloud have been linked to an irreversible reaction that implied an interaction between $\mathrm{Cr}(\mathrm{VI})$ and HAs. This chemical process could have been also confirmed by the value of apparent formation constant which was estimated, according with Lingane's equation (Rounaghi et al., 2000), to be $\log K_{\mathrm{Cr}(\mathrm{VI})-\mathrm{HAs}}=3.98$.

Actually, interaction would not be expected between anionic chromate species and HAs whose functional domains are predominantly negatively charged at $\mathrm{pH}$ 6.5. The observed interactive process, however, could be explained by supramolecular chemistry principles. HAs in fact behave as supramolecules that are able to polymerise, aggregate, form micelles and might also form supramolecular ensembles with other compounds (Fetsch and Havel, 1998; Piccolo, 2002; Steed and Atwood, 2000). As reported by Pacheco et al. (2003), the zwitterionic character of HAs allows the interaction of negatively and positively charged groups of HAs, through the micellar formations (Leita et al., 2001, 2003). In fact, organic cations like pesticides (e.g. diquat and paraquat) form rather labile HA-pesticide associates and with concomitant strong

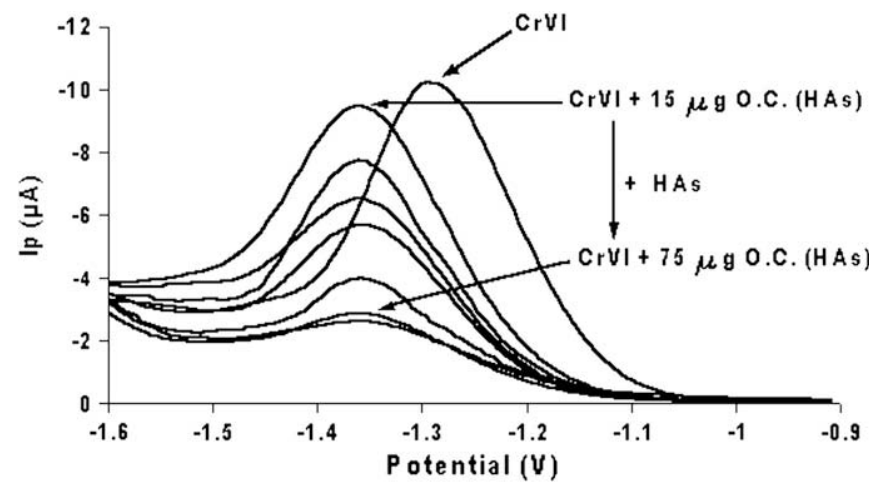

Fig. 4. $I_{\mathrm{p}} / V$ curves of amperometric titration (differential pulse stripping voltammetry, DPS) of $10 \mu \mathrm{M} \mathrm{K} \mathrm{CrO}_{4}$ before and after addition of HAs. 
interaction of HAs with pesticides' counter-anions (chloride or bromide), with the stability constant of the HA-chloride associate or \{HA-chloride supra-molecular species being rather high $(\log K=3.1)$. These results indicate that chloride is linked quite strongly with HAs, similarly to our results that lead to the formation of $\mathrm{Cr}(\mathrm{VI})$-HAs micelles.

\section{Conclusion}

The natural soil system is much more complex than the system tested, and the fate of hexavalent chromium and soil humic acids dynamics is intimately linked to the chemical, physical and biological characteristics of soil components. We are also aware that there are natural reductants that can transform the more toxic hexavalent chromium to the less toxic trivalent form and that natural attenuation of hexavalent chromium indeed readily occurs in soil (see Palmer and Puls, 1994). In this work, however, we wanted to contribute some insight into the relative persistence of chromium in its hexavalent chemical form in soil solution. On the basis of our results, it is reasonable to hypothesise that the occurrence of hexavalent chromium in soil leachate could be related to its interaction with humic acids.

\section{Acknowledgements}

This work was supported by Italian Ministry of Agriculture, Food and Forestry Policies, the Slovenian Research Agency research programme P1-0112 and by DESY and the European Community under the FP6 Programme "Structuring the European Research Area" contract RII3-CT-2004-506008 (IA-SFS). Access to synchrotron radiation facilities of HASYLAB (project II-04-065) and expert advice by Edmund Welter of HASYLAB is acknowledged.

\section{References}

Arčon, I., Mirtič, B., Kodre, A., 1998. Determination of valence states of chromium in calcium chromates by using X-Ray Absorption Near-Edge Structure (XANES) Spectroscopy. Journal of the American Ceramic Society 81 (1), 222-224.

Banks, M.K., Schwab, A.P., Henderson, C., 2006. Leaching and reduction of chromium in soil as affected by soil organic content and plants. Chemosphere 62, 255-264.

Bensalem, A., Weckhuysen, B.M., Shoonenheydt, R.A., 1997. In situ diffuse reflectance spectroscopy of supported chromium oxide catalysis: Kinetics of the reduction process with carbon monoxide. Journal of Physical Chemistry B 101 2824-2829.

Bartlett, R.J., Kimble, J.M., 1976. Behavior of chromium in soils. II. Hexavalent forms. Journal of Environmental Quality 5, 383-386.

Berlett, B.S., Levine, R.L., Stadtman, E.R., 2000. Use of isosbestic point wavelength shifts to estimate the fraction of a precursor that is converted to a given product. Analytical Biochemistry 287, 329-333.

Bianconi, A., Garcia, J., Benfatto, M., Marcelli, A., Natoli, C.R., Ruiz-Lopez, M.F., 1991. Multielectron excitations in the K-edge x-ray-absorption near-edge spectra of V, $\mathrm{Cr}$, and $\mathrm{Mn} 3 \mathrm{~d}^{0}$ compounds with tetrahedral coordination. Physical Review B 43, 6885-6892.

Borges, F., Guimarães, C., Lima, J.L.F.C., Pinto, I., Reis, S., 2005. Potentiometric studies on the complexation of copper(II) by phenolic acids as discrete ligand models of humic substances. Talanta 66, 670-673.

Campitelli, P.A., Velasco, M.I., Ceppi, S.B., 2006. Chemical and physicochemical characteristics of humic acids extracted from compost, soil and amended soil. Talanta 69, 1234-1239.

Covelo, E.F., Vega, F.A., Andrade, M.L., 2007. Competitive sorption and desorption of heavy metals by individual soil components. Journal of Hazardous Materials 140 (1-2), 308-315.

Ericksen, G.E., 1983. The Chilean nitrate deposits. American Scientist 71, 366-374.

Fetsch, D., Havel, J., 1998. Capillary zone electrophoresis for the separation and characterization of humic acids. Journal of Chromatography A 802 (1), 189-202.
Flogeac, K., Guillon, E., Aplincourt, M., 2007. Competitive sorption of metal ions onto a north-eastern France soil. Isotherms and XAFS studies. Geoderma 139, 180-189.

Fukushima, M., Nakayasu, K., Tanaka, S., Nakamura, H., 1997. Speciation analysis of chromium after reduction of chromium(VI) by humic acid. Environmental Toxicology and Chemistry 62, 207-215.

James, B.R., Bartlett, R.J., 1983. Behavior of chromium in soils. VI. Interactions between oxidation-reduction and organic complexation. Journal of Environmental Quality 12, 173-176.

Jardine, P.M., Fendorf, S.E., Mayes, M.A., Larsen, I.L., Brooks, S.C., Bailey, W.B., 1999 Fate and transport of hexavalent chromium in undisturbed heterogeneous soil. Environmental Science \& Technology 33, 2939-2944.

Korolczuk, M., Grabarczyk, M., 2002. Determination of $\mathrm{Cr}(\mathrm{VI})$ in the presence of $\mathrm{Cr}(\mathrm{III})$ and humic acid by cathodic stripping voltammetry. Microchemical Journal 72, 103-109.

Leita, L., Mori, A., De Nobili, M., Corso, G., Franco, I., Cenci, R.M., 2001. Characterization of ferricyanide-humate complexes by a voltammetric approach. Soil \& Sediment Contamination: an International Journal 10 (5), 483-496.

Leita, L., Petruzzelli, G., Fornasier, F., 2003. Ferricyanide-humate formation. Journal de Physique IV France 107, 769-772.

Lubal, P., Śiroký, D., Fetsch, D., Havel, J., 1998. The acidobasic and complexation properties of humic acids. Study of complexation of Czech humic acids with metal ions. Talanta 47, 401-412.

Lytle, F.W., Greegor, R.B., Panson, A.J., 1988. Discussion of x-ray-absorption nearedge structure: Application to $\mathrm{Cu}$ in the high-Tc superconductors $\mathrm{La}_{1.8} \mathrm{Sr}_{0.2} \mathrm{CuO}_{4}$ and $\mathrm{YBa}_{2} \mathrm{Cu}_{3} \mathrm{O}_{7}$. Physical Review B, 1550-1562.

Nakayasu, K., Fukushima, M., Sasaki, K., Tanaka, S., Nakamura, H., 1999. Comparative studies of the reduction behavior of chromium(VI) by humic substances and their precursors. Environmental Toxicology and Chemistry 18, 1085-1090.

Pacheco, M.L., Peña-Méndez, E.M., Havel, J., 2003. Supramolecular interactions of humic acids with organic and inorganic xenobiotics studied by capillary electrophoresis. Chemosphere 51 (2), 95-108.

Palmer, C.D., Wittbrodt, P.R., 1991. Processes affecting the remediation of chromium-contaminated sites. Environmental Health Perspectives 92, 25-40.

Palmer, C.D., Puls, R.W., 1994. Natural attenuation of hexavalent chromium in groundwater and soils. U.S. Environmental Protection Agency. EPA/540/5-94/ 505.

Pantelouris, A., Modrow, H., Pantelouris, M., Hormes, J., Reinen, D., 2004. The influence of coordination geometry and valency on the K-edge absorption near edge spectra of selected chromium compounds. Chemical Physics 300, 13-22.

Peña-Méndez, E.M., Havel, J., Patocka, J., 2005. Humic substances-compounds of still unknown structure: applications in agriculture, industry, environment, and biomedicine. Journal of Applied Biomedicine 3, 13-24.

Piccolo, A., 2002. The supramolecular structure of humic substances: A novel understanding of humus chemistry and implications in soil science. Advances in Agronomy 75, 57-134.

Ravel, B., Newville, M., 2005. ATHENA, ARTEMIS, HEPHAESTUS: data analysis for Xray absorption spectroscopy using IFEFFIT. Journal of Synchrotron Radiation 12 , 537-541 and XAS Analysis Software Using IFEFFIT Website, 2006. http://cars9. uchicago.edu/ ravel/software/docs.html.

Rehr, J.J., Albers, R.C., Zabinsky, S.I., 1992. High-order multiple-scattering calculations of x-ray-absorption fine structure. Physical Review Letters 69, 3397-3400.

Robertson, N., 1975. Hexavalent chromium in the ground water in Paradise Valley, Arizona. Ground Water 16 (6), 516-527.

Rounaghi, G., Chamsaz, M., Nezhadali, A, 2000. Study of complex formation between 18-crown-6 and $\mathrm{Pb}^{2+}, \mathrm{Tl}^{+}$and $\mathrm{Cd}^{2+}$ cations in binary aqueous/nonaqueous solvents using polarographic techniques (DPP and SWP). Journal of Inclusion Phenomena and Macrocyclic Chemistry 38, 153-161.

Safavi, A., Abdollahi, H., 2001. Spectrophotometric study on micelle-mediated shift in kinetic and equilibrium of complex formation between $\mathrm{Ni}^{2+}$ and 2-aminocyclopentene-1-dithiocarboxylic acid. Microchemical Journal 69, 167-175.

Steed, J.W., Atwood, J.L., 2000. Supramolecular Chemistry. John Wiley \& Sons, London.

Stewart, M.A., Jardine, P.M., Barnett, M.O., Mehlhorn, T.L., Hyder, L.K., McKay, L.D. 2003. Influence of soil geochemical and physical properties on the sorption and bioaccessibility of chromium(III). Journal of Environmental Quality 32, 129-137.

Takehira, K., Ohishi, Y., Shishido, T., Kawabata, T., Takaki, K., Zhang, O., Wang, Y. 2004. Behavior of active sites on Cr-MCM- 41 catalysts during the dehydrogenation of propane with $\mathrm{CO}_{2}$. Journal of Catalysis 224, 404-416.

Uyguner, C.S., Bekbolet, M., 2004. Evaluation of humic acid, chromium (VI) and $\mathrm{TiO}_{2}$ ternary system in relation to adsorptive interactions. Applied Catalysis, B: Environmental 49, 267-275.

Wittbrodt, P.R., Palmer, C.D., 1996. Reduction of $\mathrm{Cr}(\mathrm{VI})$ by soil humic acids. European Journal of Soil Science 47, 151-162.

Wong, J., Lytle, F.W., Messmer, R.P., Maylotte, D.H., 1984. K-edge absorption spectra of selected vanadium compounds. Physical Review B 30, 5596-5610. 